\title{
Mine Water and the Environment in Wales
}

\author{
Paul Edwards ${ }^{1}[$
}

Received: 16 April 2021 / Accepted: 12 August 2021 / Published online: 18 August 2021

(c) Springer-Verlag GmbH Germany, part of Springer Nature 2021

I was employed as a fisheries officer by the National Rivers Authority (NRA) in 1993 when an outbreak of mine water from the Ynysarwed Colliery changed the course of my career. I was asked to review the effectiveness of the emergency remedial measures, sparking an interest in mine water that led to me applying for a post as project officer on the River Pelenna Mine Water Treatment Project.

The Pelenna project was one of the first and largest wetland schemes to treat UK mine water and predated the formation of the Coal Authority in 1994. The Neath Port Talbot Council formed a partnership with the NRA, and its successor, Environment Agency Wales (EAW) in 1996 to construct wetlands to treat five mine water discharges, using emerging technologies such as reducing and alkalinity producing systems (RAPS) and ochre accretion terraces. This demonstration project used conceptual designs by SRK and Paul Younger, and was co-financed by the European Union (EU) LIFE programme. Following completion, we assessed the effectiveness and ecological benefits of the treatment systems, which demonstrated dramatic improvements in populations of invertebrates, fish, and riverine birds. Meanwhile, the Coal Authority embarked on a successful UK remediation programme for coal mine water discharges and eventually took over management of the Pelenna wetlands and the active treatment system at Ynysarwed.

With the worst of the coal mine pollution under control, EAW's attention turned to abandoned metal mines, which remained a major source of pollution and for which no funding or responsibilities had been identified. The implementation of the EU Water Framework Directive (WFD) in 2000 gave EAW new responsibilities for dealing with unregulated sources of pollution, including abandoned mines. In 2002, EAW published its Metal Mines Strategy for Wales, identifying the top 50 abandoned metal mines in Wales and the

Paul Edwards

paul.edwards@cyfoethnaturiolcymru.gov.uk

1 Natural Resources Wales, Cardiff, UK features that could facilitate or impede remediation at each site.

In 2004, we began a review of the environmental impacts of the top 50 metal mines in Wales to prioritise these mines for remediation. It was clear that a programme of constructed wetlands for treating point-source discharges, which was effective for abandoned coal mines, would not achieve the ecological status required by the WFD in metal mine impacted river catchments, due to the diffuse sources and the high solubility of metals such as $\mathrm{Zn}$ and $\mathrm{Cd}$ that were characteristic of these mine waters. Furthermore, the ecological impacts of these mines were not clearly understood and could not be predicted from compliance with environmental quality standards (EQS) alone. Following this review, we sought funding for preliminary work at some of our highest priority sites, including Cwm Rheidol and Frongoch, and planned a programme of water quality, flow, and ecological monitoring at these and other priority sites. The top priority site in Wales was Parys Mountain, but remediation was delayed at this site due to technical challenges and difficulties in quantifying benefits, particularly to the marine environment.

So, in 2007, we initiated an EU-funded project to assess the treatability of discharges from the Cwm Rheidol mine and reduce water ingress to that mine. Discharges from the two drainage adits were captured in pipes to feed a pilotscale treatment system containing a mixture of organic matter and cockle shells to increase alkalinity and precipitate metals as sulphides. The system was designed by Newcastle University's HERO Group, based on laboratory trials to identify suitable substrates, and operated until 2017. High removal rates were initially achieved for $\mathrm{Zn}, \mathrm{Pb}$, and $\mathrm{Cd}$, but a seasonal pattern emerged with lower removal rates in winter. A similar system was later used on a larger scale at Force Crag mine in Cumbria, but a lack of space at Cwm Rheidol and other steep-sided Welsh valleys has required us to seek more space-efficient treatment solutions.

From 2011 to 2013, we conducted research to apportion metal sources that were causing streams to fail WFD standards, using SIMCAT modelling software to simulate 
metal concentrations and flows throughout the most heavily impacted river catchments. These models highlighted priority sources for remediation but also the gaps in our monitoring data, especially flow data. We have since collaborated with Liverpool John Moores and Swansea universities to refine our source apportionment models using salt dilution gauging and synoptic sampling with a sodium bromide tracer.

With the support of the European Regional Development Fund, four phases of remediation were undertaken at the Frongoch mine between 2011 and 2018, with the aim of reducing surface water contact and ingress to mine waste and underground workings. The scheme included stream diversion and capping of 4 ha of mine waste, initially using compacted clay and subsequently, in areas of higher heritage value, a geosynthetic clay liner and a rolled confining layer. Remaining areas of exposed mine waste were hydroseeded with experimental botanical mixtures including biochar. Concentrations of $\mathrm{Zn}, \mathrm{Pb}$, and $\mathrm{Cd}$ were reduced by more than $80 \%$ downstream of the mine following remediation, and although concentrations are still well above EQS, invertebrate populations have showed signs of recovery. Collaborative projects with several universities have furthered our understanding of the source apportionment and ecological impacts of the Frongoch mine, notably a study of the effects of metal bio-accumulation on animal health by Nottingham University and the use of algal biomarkers with the University of Vic (LIFE Demine project).

Natural Resources Wales was formed in 2013, as a successor to EAW, and a new legislative framework was established: the Well-being of Future Generations (Wales) Act 2015 and the Environment (Wales) Act 2016. These mandated the application of sustainable development principles in our work, ensuring that the needs of the present were met without compromising the ability of future generations to meet their own needs. These principles continue to guide our decisions on how to manage pollution from abandoned mines without diminishing natural resources.

In 2017, the Welsh Government (WG) funded trials using electrochemistry and filtration to treat the mine water from the two adit discharges at Cwm Rheidol and the residual groundwater discharges at Frongoch. The Cwm Rheidol trial, run by Power and Water, used sono-electrochemistry (@soneco) while the Frongoch trial, run by Elentec, used an electrochemical coagulation system previously tested in north Wales. Both systems achieved high removal rates for $\mathrm{Zn}, \mathrm{Pb}$, and $\mathrm{Cd}$, and similar technology is now being considered for treatment of these and other priority discharges in Wales, subject to costs and sustainability. We have also facilitated trials using alternative passive systems with Durham, Swansea, and Cardiff universities. It has been fascinating to witness how the ongoing research, development and innovation has developed into successful treatment tools at abandoned mines.

Since 2018, NRW has embarked on a programme of metal mine remediation at higher priority sites, plus feasibility studies and assessments of hazards, including blowout potential, at several other sites. The priority sites for remediation in 2020/21, based on a 2016 Coal Authority prioritisation, are the Abbey Consols and Esgair Mwyn mines in the upper Teifi, an important river for salmon and other wildlife. These mines require both surface water management features and treatment options. At Abbey Consols, results of field trial dosing of sodium carbonate in 2020 informed the final design for Wales' first full-scale metal mine water demonstration treatment plant, while remediation at Esgair Mwyn is intended to prevent the loss of $\mathrm{Pb}$-rich sediment from a 50,000-t conical spoil tip. Work to reduce blowout risk from an adit roof collapse at Cwm Rheidol also continues.

NRW's remediation programme is being managed by our Geoscience team in collaboration with the Coal Authority, funded by the WG. My role in the Environmental Assessment \& Advice Team enables me to continue my involvement in metals source apportionment and ecological assessment associated with metal mine remediation. Due to the challenges of Welsh metal mines, notably sediment contamination from, in some cases, centuries of spoil heap erosion, it's unlikely that remediation of these mines will result in the rapid and spectacular ecological improvements that I witnessed on the Pelenna at the start of the millennium. A commitment to sustainable remediation targeted at the right locations, using an evidence-based approach, should, however, result in long-term benefits to wildlife and the wellbeing of local communities in the future. 